\title{
A INFLUÊNCIA DO FATOR PREÇO E EFICÁCIA DAS TÁTICAS PROMOCIONAIS NO SETOR HOTELEIRO
}

\author{
iD Cátia Sá \\ Mestrado em Economia Industrial e da Empresa \\ Escola de Economia e Gestão da Universidade do Minho. \\ Braga, Portugal \\ catia-02@hotmail.com \\ António Azevedo \\ Escola de Economia e Gestão da Universidade do Minho. \\ Braga, Portugal \\ antonioa@eeg.uminho.pt
}

\section{Resumo}

O objetivo principal deste estudo é analisar a importância do fator preço e avaliar a eficácia das táticas promocionais no setor hoteleiro. Nesse sentido foi desenvolvido um questionário divulgado online, com o intuito de identificar qual o motivo e o número de dormidas por ano em hotéis, bem como a preferência da reserva (internet versus agência de viagens), das ofertas e das promoções existentes nos hotéis, para além de analisar quanto é que os consumidores estavam dispostos a pagar por um hotel low-cost e por um hotel de luxo, traçando uma perspetiva geral do perfil do turista. A amostra contou com um total de 323 indivíduos. Os resultados do estudo permitem concluir que os atributos referentes às duas categorias de hotéis e os critérios de escolha, bem como a intenção de compra têm importância significativa tanto no montante a pagar como na preferência/satisfação do consumidor.

Palavras-chave: Turismo. Indústria hoteleira. Estratégias de preço. Táticas promocionais.

Cite como

American Psychological Association (APA)

Sá, C., \& Azevedo, A. (2020, set./dez.). A influência do fator preço e eficácia das táticas promocionais no setor hoteleiro. PODIUM Sport, Leisure and Tourism Review, São Paulo, 9(Edição Especial), 46-69.

https://doi.org/10.5585/podium.v9i4.14677. 


\title{
LA INFLUENCIA DEL FACTOR PRECIO Y LA EFICACIA DE LAS TÁCTICAS PROMOCIONALES EN EL SECTOR HOTELERO
}

\section{Resumen}

El objetivo principal de este estudio es analizar la importancia del factor precio y evaluar la eficacia de las tácticas promocionales en el sector hotelero. En este sentido, se desarrolló un cuestionario publicado online, con el fin de identificar el motivo y el número de pernoctaciones al año en hoteles, así como la preferencia de la reserva (internet versus agencia de viajes), de las ofertas y las promociones existentes en los hoteles, además de analizar cuánto estaban dispuestos a pagar los consumidores por un hotel lowcost y un hotel de lujo, trazando una perspectiva general del perfil turístico. La muestra incluyó un total de 323 individuos. Los resultados del estudio permiten concluir que los atributos referentes a las dos categorías de hoteles y los criterios de selección, así como la intención de compra, tienen una importancia significativa tanto en el monto a pagar como en la preferencia/satisfacción del consumidor.

Palabras clave: Turismo. Industria hotelera. Estrategias de precios. Tácticas promocionales.

\section{THE INFLUENCE OF THE PRICE FACTOR AND THE EFFECTIVENESS OF THE PRICE PROMOTIONAL TACTICS IN THE HOTEL SECTOR}

\begin{abstract}
The main goal of this study is to analyze the influence of the price factor and to evaluate the effectiveness of the promotional tactics in the hotel sector. In this study, it was developed an online questionnaire assessing the reason and the number of nights per year in hotels, as well as the preference of the reservation (internet versus travel agency), offers and promotions in hotels. Moreover, it assessed how much tourists were willing to pay for a low-cost hotel and a luxury hotel, outlining a general perspective of the tourist profile. The sample consisted of 323 individuals. The results allow us to conclude that the attributes of the two categories of hotels and the selection criteria as well as the intention to purchase have significant importance in the amount to be paid and in the consumer preference/satisfaction.
\end{abstract}

Keywords: Tourism. Hotel industry. Price strategies. Promotional tactics.

\section{Introdução}

O turismo tem vindo a afirmar-se ao longo dos anos como um setor estratégico da economia portuguesa, pois contribui para o crescimento do emprego e da economia, bem como para o desenvolvimento e a integração socioeconómica das regiões mais rurais, periféricas e com menores níveis de desenvolvimento (Pereira \& Ferreira, 2014).

O turismo é um dos setores industriais que mais cresce no mundo. As previsões do WTTC (World Travel and Tourism Council) para Portugal indicam um crescimento sucessivo 
até 2026, ano em que o setor deverá atingir 7,3\% do PIB, o equivalente a 14,6 mil milhões de euros.

Um dos aspetos que mais contribui para o aumento da rentabilidade do turismo reside no melhor desempenho das ferramentas e estratégias de optimização da receita, também designadas por "revenue management" (RM). Conforme Noone, McGuire \& Rohlfs (2011) e Erdem \& Jiang (2016) demonstraram, o papel da internet e das redes sociais permite uma maior interação com os clientes, o que gera novas oportunidades para a pesquisa do comportamento do consumidor durante o processo de decisão de compra.

O principal objetivo desta dissertação é analisar a influência do fator preço e avaliar a eficácia das táticas promocionais no setor hoteleiro, aqui definidas neste estudo como técnicas de alteração temporária do preço de venda de tabela como por exemplo: descontos temporários, ofertas de cupões, oferta de serviços e programas de fidelização. Para isso o artigo procura responder às seguintes questões de pesquisa:

Q.1 - Qual o comportamento e resposta do consumidor face às diferentes estratégias de preço, nomeadamente a estratégia de penetração pelo baixo preço (low cost) e a estratégia de preço premium (preço como sinal de qualidade e prestígio)?

Q.2 - Qual a eficácia das diferentes táticas promocionais mais usadas online/offline no setor da hotelaria?

\section{Revisão da literatura}

\subsection{A importância da politica de preço no processo de decisão e comportamento de compra do turista}

As características individuais dos consumidores influenciam o seu comportamento, mas a escolha final é resultado de um complexo processo composto por fatores culturais, sociais, pessoais, políticos, económicos e psicológicos. Embora outros fatores sejam importantes na decisão de compra, o preço é o principal determinante, especialmente em grupos de clientes com menos poder de compra. O preço do produto/serviço é o montante que se paga para a obtenção do mesmo. Os clientes interpretam um preço com base no conhecimento adquirido em compras anteriores. Depois disso, estabelecem um limite mínimo e um limite máximo, escolhendo depois o preço que estão dispostos a pagar (Kotler, 1998). 
Para que seja realizada uma estratégia de preço é necessário estimar a elasticidade de vários fatores do mercado envolvente, isso implica compreender as respostas dos clientes nas várias fases da decisão de compra. São exemplo disso: a compra por impulso em oposição à compra planeada, a compra no inverno contra a compra no verão (sazonalidade), a compra de presentes em contraste com a compra para uso pessoal. Para além disso, uma boa estratégia de preço envolve um bom conhecimento do ambiente competitivo e do que realmente gera valor para o cliente (Wyner, 2001).

Os consumidores não têm conhecimento dos preços praticados, mas analisam-nos para decidir o seu comportamento, perguntando-se: o preço é aceitável ou não? A partir desta dúvida, foram elaborados métodos de determinação do preço de aceitação. $\mathrm{O}$ consumidor agrupa os preços segundo diversos fatores para chegar à decisão final. $\mathrm{O}$ primeiro fator diz respeito ao montante da compra, ou seja, o cliente é mais sensível a uma compra importante, mas a sensibilidade nem sempre é proporcional ao montante da compra. O segundo fator consiste na dependência do preço em relação à perceção do risco associado à decisão de compra, ou seja, diz respeito à sensação de ter cedido à compra muito cedo ou ter pago muito caro. $\mathrm{O}$ terceiro fator referencia que a sensibilidade ao preço depende do valor da imagem associada ao produto/serviço e ao seu preço. $\mathrm{O}$ quarto fator diz respeito aos produtos de substituição. $\mathrm{O}$ último fator afirma que quando o custo é levado em consideração, a sensibilidade ao preço é mais baixa. O preço de aceitação pode variar com o tempo. Para a maior parte dos clientes este preço de aceitação é bastante inferior ao preço de venda (Lindon et al., 2003).

Para Kotler (1998), no final da compra, o consumidor é quem irá decidir se o preço do produto/serviço é o correto ou não. O mais adequado será não cobrar preços mais baixos do que o habitual, mas sim diferenciar o produto/serviço que a empresa está a oferecer, para que se possa cobrar um preço mais elevado.

Os turistas preferem cada vez mais reservar hotéis on-line por causa da conveniência e economia de tempo e custo. Lien et al. (2015) examinaram os efeitos diretos e mediadores da imagem da marca, preço percebido, confiança, valor percebido nas intenções de reserva dos consumidores. Os resultados confirmam que a maioria dos efeitos diretos e indiretos são consistentes com resultados de estudos anteriores. A imagem da marca, o preço percebido e o valor percebido são os três determinantes críticos que influenciam diretamente as intenções de compra. No entanto, o impacto da confiança sobre as intenções de compra não é significativo. 
Por outro lado, Becerra, Santaló \& Silva (2013) estudaram os efeitos da diferenciação vertical e horizontal na política de preços em uma grande amostra de hotéis em Espanha. Os hotéis com mais estrelas (ou seja, diferenciados verticalmente) oferecem descontos menores sobre os preços tabelados, além de cobrar preços mais altos. Da mesma forma, hotéis que pertencem a uma cadeia de marca (ou seja, diferenciação horizontal) também cobram preços mais altos e proporcionam descontos menores. Este estudo demonstrou que o grau de concorrência local modera o efeito da diferenciação na política de preços. A diferenciação, na verdade, protege os hotéis da pressão para reduzir os preços à medida que a concorrência aumenta, mas ser melhor parece ser mais eficaz do que apenas ser diferente.

Kuo \& Nakhata (2016) concluíram também que quando é longa a distância temporal entre o momento da compra e a data da estadia, um grande desconto é mais eficaz para aliviar as respostas negativas dos consumidores em relação aos hotéis com baixas avaliações dos consumidores. No entanto, quando um desconto de preço é apresentado como um pacote em vez de um acordo separado, um pequeno desconto torna-se tão atraente quanto um grande desconto para consumidores que compram com maior antecedência.

\subsection{Revenue (Yield) management na hotelaria}

O papel do "Revenue Management" (RM) tem sido estudado por diversos autores (Abrate \& Viglia, 2016; Erdem \& Jiang; 2016; Noone, McGuire \& Rohlfs, 2011; Pereira, 2016; Ventura \& Nogales, 2012). A principal preocupação existente passa pelos diferentes números de quartos serem vendidos a diferentes preços. $\mathrm{O}$ objetivo principal é vender o maior número de quartos ao melhor preço, mas nem sempre isto é possível. Isto acontece, pois nem sempre o número de clientes dispostos a pagar as tarifas diárias mais elevadas é suficiente, e o hotel perde dinheiro, porque possui um stock de quartos disponível que poderia ter sido vendido a um preço mais baixo a outros clientes. No entanto pode, ao tentar vender o maior número de quartos a um preço mais baixo, perder receitas de clientes que estariam dispostos a pagar taxas mais elevadas. O objetivo fundamental do Revenue Management é evitar qualquer dos dois tipos de perdas: receita ou ocupação.

O gerente hoteleiro possui duas hipóteses: vender alguns os quartos ao preço mais elevado possível ou vender todos os quartos a um preço baixo. Para evitar perdas de lucros, é necessário saber quantos quartos devem ser vendidos e a que preço, de acordo com o que cada tipo de cliente está disposto a pagar por determinado quarto (Kimes, 2008). 
A Figura 1 mostra o Spoilage que ocorre quando uma unidade hoteleira está na iminência de ser vendida. Se tivessem sido oferecidos descontos antes do último dia de venda, o número esperado de reservas poderia ter sido atingido.

A Figura 2 mostra o Spill, onde observamos como uma empresa faz, com muita precedência, vendas com desconto, perdendo a oportunidade de vender a um preço mais elevado.

Figura 1 - Curva de reservas com Spoilage

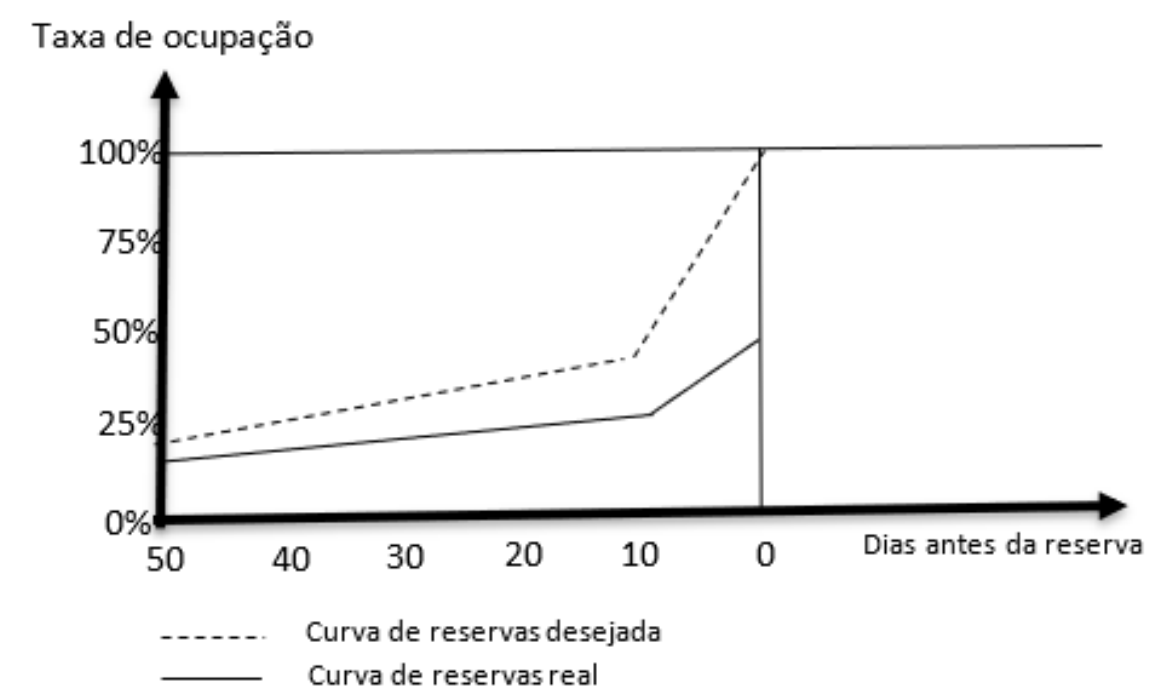

Fonte: Autores.

Figura 2 - Curva de reservas com Spill.

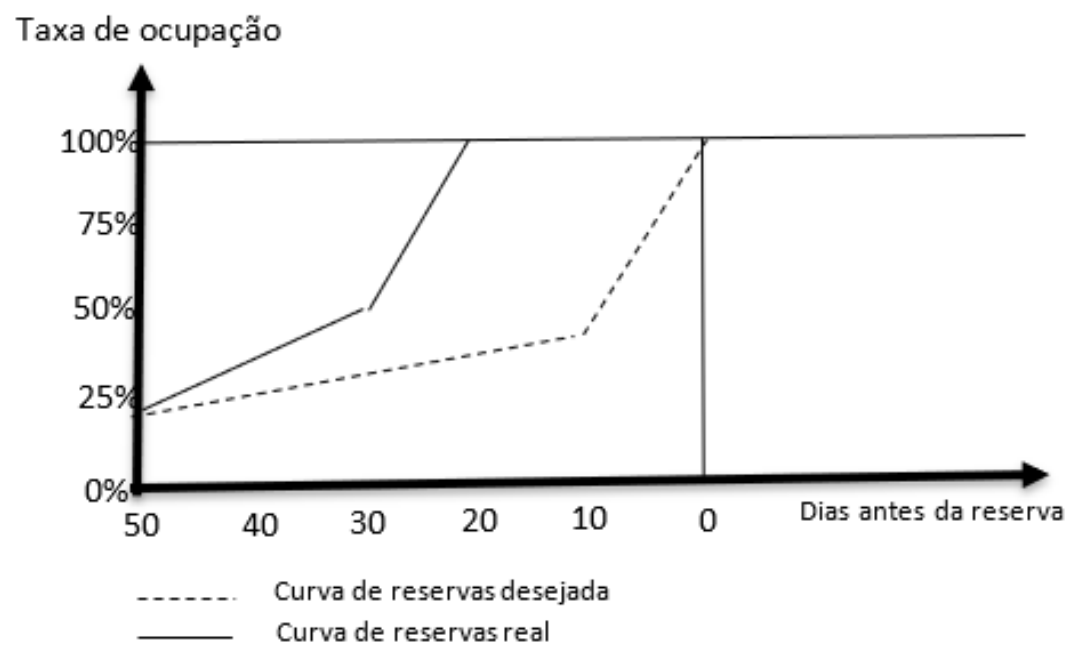

Fonte: Autores. 
Rondan-Cataluña \& Rosa-Diaz (2014) demonstraram que as variáveis preço e value for money são boas bases de segmentação de clientes do hotel, nomeadamente para distinguir os clientes entre "sensíveis ao preço - elásticos" e "não sensíveis ao preço - rígidos". Os profissionais de marketing que aplicam o revenue management devem ter em conta as perceções dos preços dos clientes e que as alterações de preços devem ser comunicadas adequadamente.

Como Kimes (2008) referiu, existem alguns meios de aumentar os preços sem criar um sentimento de injustiça nos clientes. Um deles é aumentar os preços de referência e realizar um desconto, fazendo os clientes sentirem-se especiais. Outro meio é adicionar serviços ou produtos extra à venda (ofertas), aumentando o preço, ou seja, aumentando o valor percebido. Outra hipótese ainda seria vender o serviço hoteleiro como parte de um pacote, disfarçando o preço real do serviço.

2.3 O papel das táticas de preço, promoções de vendas e mensagens pop-up de incentivo à compra

Para a perceção do valor e a definição do preço real na indústria hoteleira, importa analisar o efeito da utilização de táticas promocionais como por exemplo: descontos temporários, ofertas de cupões, oferta de serviços e programas de fidelização. Christou (2011) propôs um modelo em que o consumidor avalia cognitivamente a informação e os benefícios percebidos da promoção, que por sua vez suscita uma resposta afetiva que gera um comportamento em termos de intenção de compra/reserva.

Conforme Fall (2002) demonstrou num estudo realizado nos Estados Unidos, existem vantagens na utilização das táticas promocionais no turismo uma vez que estas podem ser financeiramente compensatórias (ou seja podem ter um retorno sobre o investimento (ROI) positivo). No entanto também podem ter implicações negativas conforme foi demonstrado por vários autores. Por exemplo Trump (2016) demonstrou que quando os prazos de reclamação dos cupões são curtos, a utilização desta tática pode gerar atitudes negativas em relação à marca do hotel.

Por outo lado, as promoções on-line são acompanhadas de mensagens pop-up que visam estimular e apressar a compra (Noone \& Mattila, 2009) e, que contribuem também para a rentabilidade financeira do hotel (Buhalis \& Mamalakis, 2015). Segundo Abrate \& Viglia (2016), para além dos atributos tangíveis e reputacionais das promoções, as variáveis 
contextuais assumem um papel relevante nas variações de preços no curto prazo (Viglia, Mauri \& Carricano, 2016). Por exemplo, segundo Abrate, Fraquelli \& Viglia (2012), pode haver diferenças entre os preços praticados quando as datas de reserva são fim de semana comparativamente aos dias úteis.

Finalmente, para definição da perceção do preço contribui ainda outros aspetos conforme demonstraram entre outros Guizzardi, Pons \& Ranieri (2017): a inclusão do pequeno almoço no preço da dormida, a existência de cauções ou a politica de reembolso no caso de cancelamento.

\subsection{Modelo teórico e desenvolvimento de hipóteses}

Com base nas contribuições dos modelos e constructos analisados na revisão da literatura, nomeadamente os propostos por Noone \& Mattila (2009), Christou (2011), os autores propõe o seguinte modelo teórico alternativo - (ver Figura 3).

Este modelo serviu de base para determinar as hipóteses a estudar. A categoria do hotel, normalmente identificada pelo número de estrelas ${ }^{1}$ é uma das variáveis independentes considerada frequentemente nos estudos (Abrate, Fraquelli \& Viglia, 2012; Guizzardi, Pons \& Ranieri, 2017). Neste estudo optou-se por analisar dois cenários opostos (hotel low-cost- 2 estrelas versus hotel de luxo de 5 estrelas) conforme está postulado na hipótese seguinte:

H1: A categoria de hotel (low-cost vs luxo) influencia a resposta à estratégia de preço?

Tal como Christou (2011) e Noone \& Mattila (2009) propuseram as táticas promocionais influenciam positiva ou negativamente a avaliação do hotel, aqui designada por atitude em relação à marca $(\mathrm{Ab})$ na hipótese $\mathrm{H} 2 \mathrm{a}$ e por consequência o preço máximo a pagar (WTP), na hipótese H2b.

H2a, b: As importâncias percebidas das táticas promocionais de preço estão correlacionadas com a $\mathrm{Ab}(\mathrm{H} 2 \mathrm{a})$ e com o preço máximo a pagar (WTP) $(\mathrm{H} 2 \mathrm{~b})$ ?

${ }^{1}$ (http://www.classificacao.turismo.gov.br/MTUR-classificacao/mtur-site/Sobre.action) 
Figura 3 - Modelo teórico do estudo realizado

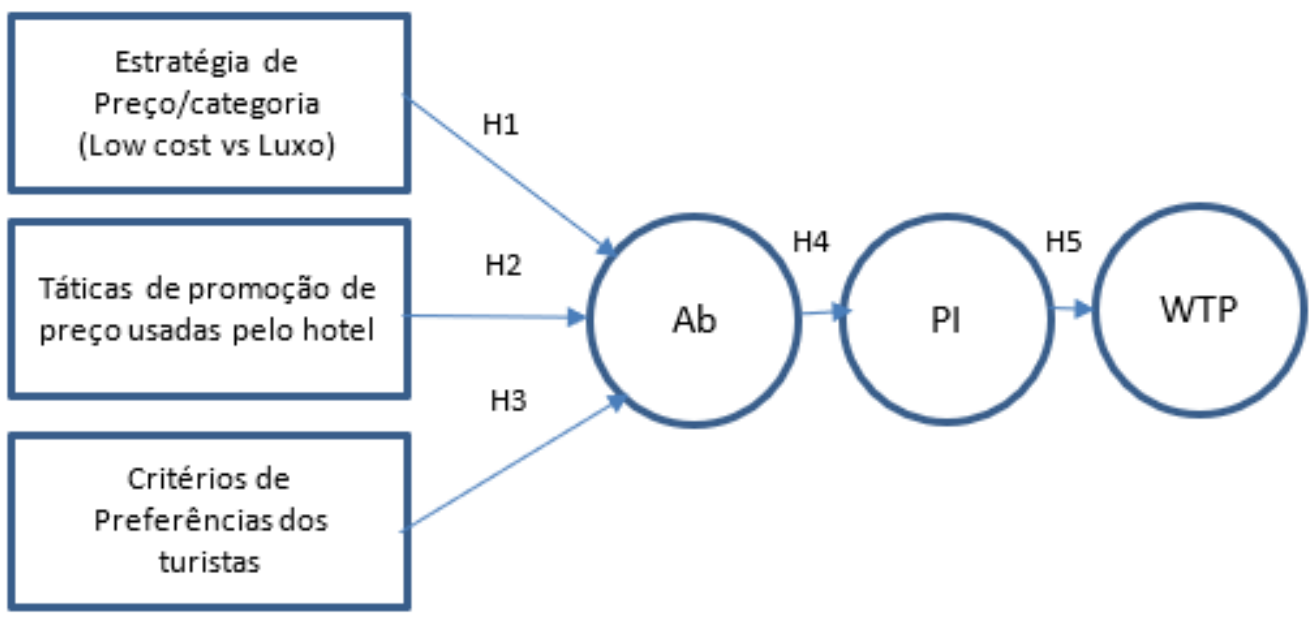

Legenda: $\mathrm{Ab}$ - Atitude face às duas tipologias de hotéis; PI - Intenção de compra; WTP - Preço máximo a pagar. Fonte: Autores.

Conforme referiram Abrate \& Viglia (2016), os atributos tangíveis, aqui designados por critérios de preferência de escolha, podem determinar as medidas dependentes do modelo, conforme é postulado na hipóteses H3a,b.

H3a,b: Os critérios de preferência dos consumidores estão positivamente correlacionados/ são preditores de Ab (H3a) e WTP (H3b)?

Finalmente, nas hipóteses seguintes propõe-se as hipóteses H4 e H5, que estão alinhadas com os modelos de decisão de compra propostos por diversos autores (Zhang et al, 2014), em que se procura confirmar a correlação positiva entre a atitude em relação à marca/ hotel, a intenção de compra/reserva e o preço máximo a pagar (WTP):

H4: A atitude em relação às duas categorias de hotéis (Ab) está positivamente correlacionada com a intenção de compra (PI)?

H5: A intenção de compra (PI) está positivamente correlacionada com o preço máximo a pagar (WTP)? 


\section{Metodologia}

Para testar as hipótese formuladas neste estudo, foi desenvolvido um questionário que foi posteriormente divulgado online, nomeadamente na rede social Facebook e no correio eletrónico académico. $\mathrm{O}$ texto das questões do estudo está disponivel nas tabelas seguintes. Pretendeu-se identificar as variáveis relevantes no setor hoteleiro que permitem caracterizar o turista (qual o motivo e o número de dormidas nos hotéis por ano, bem como a preferência na reserva, nas ofertas e na promoção dos hotéis). Para além disso, procurou-se saber quanto é que os consumidores estavam dispostos a pagar (WTP) por um hotel low-cost e por um de 5 estrelas. O período de recolha de dados decorreu entre 15 de Dezembro de 2016 e 15 de Março de 2017, dados esses que foram posteriormente analisados no programa estatístico SPSS.

\subsection{Caracterização da amostra}

A amostra é caracterizada por 323 indivíduos, 206 mulheres $(63,8 \%)$ e 117 homens (36,2\%). Em relação às idades mencionadas no questionário, a média das idades é 28,55 (DP=10,30) mínima foi 18 anos e a idade máxima foi 70 . As habilitações literárias dos indivíduos dividiram-se em ensino secundário e cursos superiores, cabendo 72 à primeira categoria $(22,3 \%)$ e 251 à segunda $(77,7 \%)$. No que se refere às profissões dos inquiridos, a frequência mais elevada (156) é relativa aos desempregados/estudantes (48,3\%). A profissão menos frequente são os operários especializados/ não especializados com 14 respostas (4,3\%). O agregado familiar varia entre $1(11,1 \%)$ e $6(2,5 \%)$ pessoas, sendo que a maior percentagem se verifica nas famílias com 4 elementos $(32,5 \%)$.

Relativamente ao número de dormidas num hotel por ano, os valores variam entre 0 $(11,1 \%)$ e $120(0,3 \%)$, observando-se maior percentagem nas 10 dormidas (10,8\%). Subdividindo-se o motivo da viagem em três categorias, foram obtidos os seguintes resultados: lazer $(87,9 \%)$, trabalho/negócios $(10,5 \%)$ e competições desportivas/culturais (1,5\%). Como foi abordado na revisão de literatura, o turismo de negócios terá um enorme crescimento nos próximos anos, sendo já observável aqui uma avantajada percentagem.

O questionário ditou que a preferência dos consumidores se situa na internet com 249 respostas $(77,1 \%)$ enquanto as agências de viagens apenas obtiveram 74 respostas $(22,9 \%)$. Neste critério importa salientar que quando mencionado o fator internet, o intuito era fazer referência ao booking.com, trivago.pt, momondo.pt, entre outros. 


\subsection{Cenários}

A influência da estratégia de preço do hotel foi operacionalizada através da exposição do respondente a dois cenários antagónicos: Cenário 1 - estratégia de penetração pelo baixo preço (também designada por low cost); Cenário 2- estratégia de preço prémium:

Cenário 1: Um hotel low-cost (2 estrelas) com a informação disponibilizando as seguintes características: económico; receção garantida $12 \mathrm{~h}$ por dia ou $24 \mathrm{~h}$ por telefone; serviço de transporte de bagagem no horário em que a receção está aberta; telefone, cofre, televisão; limpeza de quartos uma vez por dia; troca de lençóis duas vez por semana; troca de toalhas três vezes por semana; casas de banho partilhadas ou $80 \%$ privadas; quartos duplos de pelo menos 14 metros quadrados com cadeira, cómoda, mesa, espelho e tomada elétrica; restaurante; elevador caso tenha mais do que um andar.

Cenário 2 - Um hotel de luxo (5 estrelas) com as seguintes características: receção garantida 24 horas por dia; atendimento em três idiomas estrangeiros; serviço de transporte de bagagem 24 horas; telefone, cofre, televisão; limpeza de quartos todos os dias; casas de banho privadas; serviço de lavandaria com entrega no mesmo dia; quartos duplos de pelo menos 16 metros quadrados com cadeira, cómoda, mesa, espelho, tomada elétrica, minibar, poltrona e ar condicionado; conexão à internet em todo o hotel; parque de estacionamento; serviço de quartos; bar; restaurante; vários elevadores; spa, massagens, piscina e reserva de excursões (Turismo de Portugal, 2017).

Segundo Enz, Canina \& van der Rest (2015), num estudo com 4000 hotéis europeus no período 2004-2013, os hotéis que optam por um posicionamento com um preço elevado comparativamente ao preço médio do destino, tem um maior RevPar.

\section{Discussão dos resultados}

Na Tabela 1 apresentam-se os resultados das questões relativas respetivamente ao hotel low cost e o ao hotel de luxo, nomeadamente no que diz respeito à atitude em relação ao hotel $(\mathrm{Ab})$, intenção de compra (PI), recomendação (WOM), preço máximo a pagar (WTP) e outros aspetos que diretamente ou indiretamente afetam o preço da dormida. Por outro lado na Tabela 2 apresenta-se a importância dos critérios de escolha de um hotel.

\subsection{Hotel Low-cost (**)}

A opção de reembolso é "10- muito importante" para 75 dos interrogados $(23,2 \%)$. O reembolso surge na hotelaria como uma forma do hotel cobrar o valor da reserva 
Santos, E. S., \& Carvalho, M. J. (2020, set./dez.). Redes de colaboração científica e análise de políticas públicas desportivas locais no Brasil e em Portugal

anteriormente ao ato ou no próprio dia da reserva, de forma a desencorajar as desistências e "no shows".

Independentemente de se tratar de um hotel low-cost, os consumidores fazem questão de obter o pequeno-almoço na sua estadia, pois obteve-se 86 respostas $(26,6 \%)$ na classe $(10$ muito importante; escala de 0 a 10$)$.

Tabela 1 - Médias e desvios padrão da Atitude em relação ao hotel (Ab), intenção de compra (PI), preço máximo a pagar (WTP), recomendação e importâncias das opções relativas ao preço do hotel

\begin{tabular}{|c|c|c|}
\hline & Média & $\begin{array}{l}\text { Desvio } \\
\text { Padrão }\end{array}$ \\
\hline \multicolumn{3}{|l|}{ Hotel Low-cost } \\
\hline Numa escala de 0-10, gostou deste hotel? & 5,80 & 2,092 \\
\hline Numa escala de 0-10, qual a sua intenção de reservar o hotel & 5,31 & 2,338 \\
\hline Qual o montante que está disposto a pagar por um quarto neste hotel (em euros)? & 33,36 & 18,082 \\
\hline Numa escala de 0-10, recomendaria este hotel a um amigo? & 5,22 & 2,207 \\
\hline $\begin{array}{l}\text { A opção de reembolso, neste caso, é importante (entenda-se por reembolso o ato } \\
\text { do hotel cobrar o valor da reserva anteriormente quando a faz ou no próprio dia }\end{array}$ & 6,85 & 2,601 \\
\hline $\begin{array}{l}\text { Sente a necessidade de incluir a opção de pequeno-almoço na sua estadia, nesta } \\
\text { categoria de hotel? }\end{array}$ & 6,71 & 3,040 \\
\hline $\begin{array}{l}\text { Aceita o pedido de caução que este hotel exige (se selecionar valores entre 5-10, } \\
\text { por favor, responda à próxima questão)? }\end{array}$ & 4,71 & 2,463 \\
\hline $\begin{array}{l}\text { Qual a percentagem de desconto comercial que considera justa para pernoitar } \\
\text { neste hotel? }\end{array}$ & $11,92 \%$ & $6,36 \%$ \\
\hline \multicolumn{3}{|l|}{ Hotel de Luxo } \\
\hline Numa escala de 0-10, gostou deste hotel? & 8,90 & 1,389 \\
\hline Numa escala de 0-10, qual a sua intenção de reservar o hotel & 7,42 & 2,456 \\
\hline Qual o montante que está disposto a pagar por um quarto neste hotel (em euros)? & 103,04 & 148,082 \\
\hline Numa escala de 0-10, recomendaria este hotel a um amigo? & 7,92 & 1,981 \\
\hline A opção de reembolso, neste caso, é importante? & 7,39 & 2,422 \\
\hline $\begin{array}{l}\text { Sente a necessidade de incluir a opção de pequeno-almoço na sua estadia, nesta } \\
\text { categoria de hotel? }\end{array}$ & 8,52 & 2,089 \\
\hline $\begin{array}{l}\text { Aceita o pedido de caução que este hotel exige (se selecionar valores entre 5-10, } \\
\text { por favor, responda à próxima questão)? }\end{array}$ & 5,68 & 2,692 \\
\hline $\begin{array}{l}\text { Qual a percentagem de desconto comercial que considera justa para pernoitar } \\
\text { neste hotel? }\end{array}$ & $14,91 \%$ & $6,33 \%$ \\
\hline
\end{tabular}

Fonte: Autores. 
Devido à categoria do hotel, os consumidores não dão importância ao fator "caução". A caução é a forma de garantia que os clientes dão ao hotel, podendo assim, mais uma vez, se protegerem de danos. Apesar de não darem importância à componente "caução", (como a resposta era obrigatória) escolheram a opção " $10 \%$ do valor da dormida" como percentagem de caução, com 151 respostas $(34,7 \%)$.

No que concerne à percentagem de desconto para esta categoria de hotel, foi escolhido os 10\%, com 181 resultados (56\%). Apesar de não ser indiferente o desconto para o consumidor, pois não escolheram $0 \%$, também não consideram que seja necessário $20 \%$, pois acham que nesta categoria de hotel o preço não será muito elevado.

Tabela 2- Importância dos critérios de escolha de um hotel

\begin{tabular}{|l|r|r|}
\hline Critério de escolha & Média & $\begin{array}{r}\text { Desvio } \\
\text { Padrão }\end{array}$ \\
\hline Receção aberta 24 horas & 8,82 & 1,575 \\
Conforto & 9,46 & 0,933 \\
Higiene & 9,84 & 0,580 \\
Simpatia dos funcionários & 9,20 & 1,058 \\
Qualidade das refeições & 9,14 & 1,332 \\
Serviço de quartos & 8,63 & 1,944 \\
Localização & 8,94 & 1,237 \\
Piscina & 7,53 & 2,252 \\
Spa & 6,72 & 2,632 \\
Ginásio & 5,72 & 2,882 \\
Decoração & 7,57 & 1,836 \\
Parque de estacionamento & 8,16 & 2,132 \\
Acesso a transportes públicos & 8,28 & 1,827 \\
Acesso Wi-Fi gratuito, disponível em todo o hotel & 9,20 & 1,377 \\
Comodidades para Pessoas com Mobilidade Condicionada & 8,54 & 2,337 \\
Admissão de animais de estimação & 6,13 & 3,099 \\
Serviços de transportes de/para o aeroporto & 8,45 & 1,823 \\
\hline
\end{tabular}

Fonte: Autores.

\subsection{Hotel de Luxo (*****)}

Tendo em conta os gostos dos inquiridos sobre este hotel, numa escala de 0 a 10, 137 $(42,4 \%)$ responderam (10-muito bom). Quanto à intenção de reservar o hotel, mais uma vez, a 
frequência das respostas situa-se no 10 , com 72 respostas $(22,3 \%)$. No que se refere à questão de recomendar este hotel, a concentração de respostas encontra-se no 10, com 81 respostas $(25,1 \%)$. A opção de reembolso é importante para os interrogados, pois a maior frequência encontra-se no 10 , numa escala de 0 a 10 , com 91 respostas $(28,2 \%)$. Por se tratar de um hotel de luxo, os consumidores fazem questão de obter o pequeno-almoço na sua estadia, pois obtevese 154 respostas $(47,7 \%)$ no 10 , numa escala de 0 a 10.

Devido à categoria do hotel, seria de esperar que os consumidores dessem uma certa importância ao fator "caução", mas não foi o caso, pois a escala com mais frequência é o 5, numa escala de 0 a 10, com 56 respostas (17,3\%). Apesar de não darem a determinada importância à componente "caução", escolheram a opção "10\% do valor da dormida" como percentagem de caução, com 125 respostas $(38,7 \%)$. No que concerne à percentagem de desconto para esta categoria de hotel, foi escolhido os $20 \%$, com 183 resultados $(56,7 \%)$. Esta categoria de hotel, por si só, leva ao cliente a antever que o preço seja um pouco mais elevado do que o "normal", por isso escolherem o desconto mais elevado nas opções dadas.

\subsection{Influência das promoções de preço}

Na Tabela 3, apresentam-se as médias e desvios padrão do grau de influência para os diferentes tipos de táticas promocionais que são usadas pelos operadores e portais de reserva. Assim a informação pop-up "preço de ocasião", oferta de transfer ou de uma refeição gratuita foram as táticas percebidas como mais influentes para a decisão de compra. Já as informações sobre o ritmo de reservas ("uma pessoa a reservar o hotel", "5 pessoas a ver o quarto" ou "última reserva feita à uma hora") parecem não ser muito importantes para os inquiridos. 
Santos, E. S., \& Carvalho, M. J. (2020, set./dez.). Redes de colaboração científica e análise de políticas públicas desportivas locais no Brasil e em Portugal

Tabela 3 - Média e desvio padrão do grau de influência da tática promocional medido numa escala 1-10

\begin{tabular}{|c|c|c|}
\hline Táticas Promocionais & Média & Desvio Padrão \\
\hline Preço ocasião & 8,17 & 1,846 \\
\hline Oferta de transfer para o aeroporto & 8,08 & 2,075 \\
\hline Um refeição gratuita & 8,00 & 2,263 \\
\hline Um voucher para o spa & 7,85 & 2,250 \\
\hline Uma visita à cidade & 7,78 & 2,249 \\
\hline Bebidas gratuitas durante a estadia & 7,55 & 2,578 \\
\hline Um bilhete para um museu/parque diversões & 7,54 & 2,236 \\
\hline Tarifa diária mais baixa para os próximos 21 dias & 7,48 & 2,111 \\
\hline Oferta de 1 dormida na compra de 3 & 7,34 & 2,563 \\
\hline Um voucher de desconto para uma próxima estadia & 7,30 & 2,514 \\
\hline Um bilhete de espetáculo & 7,13 & 2,496 \\
\hline Oferta de cabaz com produtos regionais & 6,78 & 2,684 \\
\hline Campeão de vendas & 6,72 & 2,605 \\
\hline Último quarto & 6,62 & 2,834 \\
\hline Reservado 18 vezes hoje & 5,89 & 2,754 \\
\hline Cartão fidelidade com acumulação de pontos & 5,79 & 2,869 \\
\hline Uma pessoa a reservar este hotel & 5,57 & 2,669 \\
\hline 5 pessoas a ver o quarto & 5,37 & 2,708 \\
\hline Última reserva feita há 1 hora & 5,28 & 2,771 \\
\hline Número de respostas válido & 323 & \\
\hline
\end{tabular}

Fonte: Autores.

\subsubsection{Influência do género na resposta às táticas promocionais}

Por outro lado conforme se pode ver na Tabela 4, para algumas táticas promocionais, segundo o teste t de Student, verificaram-se diferenças significativas entre os inquiridos do sexo masculino e os do sexo feminino no que diz respeito à influência sobre a decisão de compra, uma vez que as mulheres atribuíram uma maior importância ou influência a estas táticas. 
Tabela 4 - Influência do género na perceção da influência das táticas promocionais: diferenças significativas segundo o teste $t$ de Student

\begin{tabular}{|c|c|c|c|c|c|c|c|}
\hline & & $\mathrm{N}$ & Media & DP & $\mathrm{t}$ & $\mathrm{gl}$ & $\mathrm{p}$ \\
\hline \multirow[t]{2}{*}{ Reservado 18 vezes hoje } & $\mathrm{M}$ & 206 & 6,14 & 2,709 & \multirow[t]{2}{*}{2,181} & \multirow[t]{2}{*}{321} & \multirow[t]{2}{*}{0,030} \\
\hline & $\mathrm{H}$ & 117 & 5,44 & 2,790 & & & \\
\hline \multirow[t]{2}{*}{ Um refeição gratuita } & $\mathrm{M}$ & 206 & 8,26 & 2,182 & \multirow[t]{2}{*}{2,825} & \multirow[t]{2}{*}{321} & \multirow[t]{2}{*}{0,005} \\
\hline & $\mathrm{H}$ & 117 & 7,53 & 2,336 & & & \\
\hline \multirow[t]{2}{*}{ Um voucher para o spa } & $\mathrm{M}$ & 206 & 8,10 & 2,023 & \multirow[t]{2}{*}{2,581} & \multirow[t]{2}{*}{199,369} & \multirow[t]{2}{*}{0,011} \\
\hline & $\mathrm{H}$ & 117 & 7,39 & 2,549 & & & \\
\hline \multirow[t]{2}{*}{ Um bilhete de espetáculo } & $\mathrm{M}$ & 206 & 7,51 & 2,125 & \multirow[t]{2}{*}{3,468} & \multirow[t]{2}{*}{186,303} & \multirow[t]{2}{*}{0,001} \\
\hline & $\mathrm{H}$ & 117 & 6,44 & 2,929 & & & \\
\hline \multirow{2}{*}{$\begin{array}{l}\text { Um bilhete para um museu/parque } \\
\text { diversões }\end{array}$} & $\mathrm{M}$ & 206 & 7,89 & 1,908 & \multirow[t]{2}{*}{3,530} & \multirow[t]{2}{*}{187,096} & \multirow[t]{2}{*}{0,001} \\
\hline & $\mathrm{H}$ & 117 & 6,91 & 2,615 & & & \\
\hline \multirow[t]{2}{*}{ Uma visita à cidade } & $\mathrm{M}$ & 206 & 8,12 & 1,925 & \multirow[t]{2}{*}{3,359} & \multirow[t]{2}{*}{187,408} & \multirow[t]{2}{*}{0,001} \\
\hline & $\mathrm{H}$ & 117 & 7,19 & 2,632 & & & \\
\hline
\end{tabular}

Legenda: H- homens; M- Mulheres; N- número de respondentes; DP- Desvio Padrão; t- teste t de Student; glgraus de liberdade; $p$ - nivel de significância $(\mathrm{p}<0,05)$.

Fonte: Autores.

\subsection{Testes de hipóteses}

Para confirmar a influência das táticas promocionais (como postulado na hipótese H2) e dos critérios de preferência (ver hipótese H3) na atitude em relação ao hotel (Ab) para os diferentes cenários (conforme postulado na hipótese H1), realizou uma regressão linear múltipla usando o método Stepwise. Assim, para o caso do hotel low-cost, pode-se ver na Tabela 5 que a atitude em relação ao hotel é explicada pela aceitação da caução, pela informação de que o hotel tem procura ("última reserva foi há uma hora), pela importância atribuída à acessibilidade por transportes públicos. No entanto quem valoriza a existência de Spa's tenderá a ter uma opinião desfavorável em relação a este hotel.

Já no caso do hotel de luxo (ver Tabela 6), a atitude em relação ao hotel de luxo (Ab) é explicada positivamente pela importância de um conjunto de critérios de preferência (acesso wi-fi, existência de piscina e simpatia dos funcionários), pela aceitação do pedido de caução, pela inclusão do pequeno almoço, e pelas táticas promocionais ("5 pessoas a ver o quarto", bebidas gratuitas e voucher de desconto). A importância atribuída à decoração pode neste caso influenciar negativamente a $\mathrm{Ab}$, sendo que os inquiridos mais velhos parecem ser mais exigentes na avaliação. Conclui-se portanto que o conjunto de preditores significativos depende da categoria e da politica de preço associada o que suporta a hipótese H1. 
Tabela 5 -Preditores da Atitude em relação à marca $(\mathrm{Ab})$ do hotel low cost, obtidos por regressão linear múltipla

\begin{tabular}{|c|c|c|c|c|c|}
\hline \multirow{2}{*}{$\left(R^{2}=0,171 ; F=16,374 ; p<0,000\right)$} & \multicolumn{2}{|c|}{$\begin{array}{l}\text { Coeficientes não } \\
\text { padronizados }\end{array}$} & \multirow{2}{*}{$\begin{array}{c}\begin{array}{c}\text { Coeficientes } \\
\text { padronizados }\end{array} \\
\underline{\text { Beta }}\end{array}$} & \multirow[t]{2}{*}{$\mathbf{t}$} & \multirow[t]{2}{*}{ Sig. } \\
\hline & $\underline{B}$ & $\underline{\text { Erro }}$ & & & \\
\hline (Constante) & 3,718 & 0,565 & & 6,578 & 0,000 \\
\hline $\begin{array}{l}\text { Aceitação do pedido de caução que o hotel } \\
\text { exige }\end{array}$ & 0,235 & 0,044 & 0,276 & 5,306 & 0,000 \\
\hline "Última reserva feita há 1 hora" & 0,121 & 0,041 & 0,160 & 2,979 & 0,003 \\
\hline Spa & $-0,160$ & 0,042 & $-0,201$ & $-3,785$ & 0,000 \\
\hline Acesso a transportes públicos & 0,171 & 0,060 & 0,149 & 2,867 & 0,004 \\
\hline
\end{tabular}

Fonte: Autores.

Tabela 6 - Preditores da Atitude em relação à marca $(\mathrm{Ab})$ do hotel de luxo, obtidos por regressão linear múltipla

\begin{tabular}{|c|c|c|c|c|c|}
\hline \multirow[t]{2}{*}{$\left(R^{2}=0,276 ; \mathrm{F}=11,907 ; \mathrm{p}<0,000\right)}$. & \multicolumn{2}{|c|}{$\begin{array}{l}\text { Coeficientes não } \\
\text { padronizados }\end{array}$} & \multirow{2}{*}{$\begin{array}{c}\begin{array}{c}\text { Coeficientes } \\
\text { padronizados }\end{array} \\
\underline{\text { Beta }}\end{array}$} & \multirow[t]{2}{*}{$\mathbf{t}$} & \multirow[t]{2}{*}{ Sig. } \\
\hline & $\underline{\mathrm{B}}$ & $\underline{\underline{\text { Erro }}}$ & & & \\
\hline (Constante) & 5,523 & 0,759 & & 7,276 & 0,000 \\
\hline Idade & $-0,024$ & 0,007 & $-0,178$ & $-3,559$ & 0,000 \\
\hline Aceitação do pedido de caução que o hotel exige & 0,057 & 0,026 & 0,110 & 2,169 & 0,031 \\
\hline $\begin{array}{l}\text { Sente a necessidade de incluir a opção de } \\
\text { pequeno-almoço na sua estadia }\end{array}$ & 0,032 & 0,034 & 0,048 & 0,951 & 0,342 \\
\hline 5 pessoas a ver o quarto & 0,043 & 0,027 & 0,084 & 1,567 & 0,118 \\
\hline Bebidas gratuitas durante a estadia & 0,082 & 0,030 & 0,152 & 2,771 & 0,006 \\
\hline $\begin{array}{l}\text { Um voucher de desconto para uma próxima } \\
\text { estadia }\end{array}$ & 0,051 & 0,030 & 0,092 & 1,705 & 0,089 \\
\hline Acesso Wi-Fi gratuito, disponível em todo o hotel & 0,127 & 0,053 & 0,126 & 2,385 & 0,018 \\
\hline Decoração & $-0,157$ & 0,043 & $-0,208$ & $-3,644$ & 0,000 \\
\hline Piscina & 0,110 & 0,036 & 0,178 & 3,050 & 0,002 \\
\hline Simpatia dos funcionários & 0,157 & 0,070 & 0,119 & 2,221 & 0,027 \\
\hline
\end{tabular}

a. Variável Dependente: Numa escala de 0-10, gostou deste hotel? 
Na Tabela 7 pode-se ver que existem coeficientes de correlação de Spearman positivos e significativos $(\mathrm{p}<0,01)$ entre o preço máximo a pagar(WTP) e a atitude em relação ao hotel $(\mathrm{Ab})$, a intenção de reservar (PI), recomendação (WOM), o que suporta as hipóteses H4 e H5. Por outro lado, confirmando a hipótese $\mathrm{H} 2 \mathrm{a}$, para quase todas táticas promocionais referidas na também existem correlações positivas significativas $(\mathrm{p}<0,01)$ com a atitude em relação ao hotel ou com a intenção de compra. Mas já o mesmo não se verifica em relação ao preço máximo a pagar o que implica a rejeição da hipótese $\mathrm{H} 2 \mathrm{~b}$.

Tabela 7 - Coeficientes de correlação de Spearman entre as táticas promocionais de preço e medidas de resposta do consumidor (Ab, PI, WOM e WTP)

\begin{tabular}{|c|c|c|c|c|c|c|c|c|}
\hline \multirow{2}{*}{$\begin{array}{l}\text { Resposta vs Táticas de } \\
\text { Promoções de preço }\end{array}$} & \multicolumn{4}{|c|}{ Hotel Low cost $2^{*}$} & \multicolumn{4}{|c|}{ Hotel de Luxo 5* } \\
\hline & $\mathrm{Ab}$ & PI & WOM & WTP & $\mathrm{Ab}$ & PI & WOM & WTP \\
\hline Ab- Atitude em relação ao hotel & 1,000 &, $821^{* *}$ &, $810^{* * *}$ & $179^{* *}$ & 1,000 &, $447^{* *}$ &, $600^{* * *}$ &, $134^{*}$ \\
\hline PI- Intenção de reserva &, $821^{* * *}$ & 1,000 &, $877^{* *}$ &, $185^{* *}$ &, $447^{* * *}$ & 1,000 &, $668^{* * *}$ &, $166^{* *}$ \\
\hline WOM- Recomendação &, $810^{* *}$ &, $877^{* *}$ & 1,000 & $219^{* *}$ &, $600^{* * *}$ &, $668^{* *}$ & 1,000 & $175^{* *}$ \\
\hline WTP- Preço máximo a pagar & $179^{* *}$ &, $185^{* *}$ &, $219^{* *}$ & 1,000 & $134^{*}$ &, $166^{* *}$ & $175^{* *}$ & 1,000 \\
\hline Preço ocasião & $127^{*}$ & $123^{*}$ &, $149^{* *}$ & &, $204^{* *}$ & 0,107 & $175^{* *}$ &, $117^{*}$ \\
\hline Último quarto &, $130^{*}$ &, $155^{* *}$ &, $191^{* *}$ & &, $151^{* *}$ & $159^{* *}$ &, $222^{* *}$ & \\
\hline Uma pessoa a reservar este hotel & ,202** &, $225^{* *}$ &, $266^{* *}$ & &, $250^{* *}$ &, $256^{* *}$ & ,319** & \\
\hline 5 pessoas a ver o quarto & $170^{* *}$ &, $171^{* *}$ &, $206^{* *}$ & &, $256^{* * *}$ &, $258^{* *}$ & $237^{* *}$ & \\
\hline Última reserva feita há 1 hora &, $182^{* * *}$ &, $142^{*}$ &, $197^{* *}$ & & $210^{* * *}$ &, $202^{* *}$ & $275^{\text {*** }}$ & \\
\hline $\begin{array}{l}\text { Tarifa diária mais baixa para os } \\
\text { próximos } 21 \text { dias }\end{array}$ &, $144^{* *}$ &, $133^{*}$ & & &, $194^{* *}$ & & & \\
\hline Reservado 18 vezes hoje &, $180^{* *}$ &, $212^{* *}$ &, $204^{* *}$ & &, $265^{\text {** }}$ &, $233^{* *}$ &, $215^{* *}$ & \\
\hline Campeão de vendas & & & $127^{*}$ & &, $222^{* *}$ &, $241^{* *}$ & ,270** & $117^{*}$ \\
\hline Uma refeição gratuita &, $162^{* *}$ &, $162^{* *}$ & $137^{*}$ & &, $305^{* *}$ &, $147^{* *}$ &, $188^{* *}$ & \\
\hline $\begin{array}{l}\text { Bebidas gratuitas durante a } \\
\text { estadia }\end{array}$ & & & & &, $297^{\text {*** }}$ &, $217^{* *}$ & $306^{* *}$ & \\
\hline $\begin{array}{l}\text { Oferta de cabaz com produtos } \\
\text { regionais }\end{array}$ &, $125^{*}$ &, $166^{* *}$ &, $183^{* *}$ & &, $212^{* *}$ & & $225^{* *}$ &, $135^{*}$ \\
\hline Um voucher para o spa & & & & & $271^{* *}$ &, $218^{* *}$ & $286^{* *}$ &, $121^{*}$ \\
\hline Um bilhete de espetáculo &, $159^{* *}$ &, $167^{* *}$ &, $202^{* *}$ & & $201^{* * *}$ &, $129^{*}$ & ,236 & \\
\hline $\begin{array}{l}\text { Um bilhete para um } \\
\text { museu/parque diversões }\end{array}$ & $153^{* *}$ &, $155^{* *}$ &, $164^{* *}$ & &, $191^{\text {** }}$ &, $134^{*}$ & $196^{* *}$ &, $114^{*}$ \\
\hline
\end{tabular}




\begin{tabular}{|c|c|c|c|c|c|c|c|}
\hline Uma visita à cidade &, $138^{*}$ &, $153^{* *}$ &, $147^{* *}$ &, $221^{* *}$ &, $159^{* * *}$ &, $217^{* *}$ & \\
\hline $\begin{array}{l}\text { Um voucher de desconto para } \\
\text { uma próxima estadia }\end{array}$ & & &, $124^{*}$ & $296^{* *}$ & $356^{* *}$ & $356^{* *}$ & $180^{* * *}$ \\
\hline $\begin{array}{l}\text { Oferta de transfer para o } \\
\text { aeroporto }\end{array}$ & & & &, $235^{* *}$ & ,200** &, $208^{* *}$ & \\
\hline $\begin{array}{l}\text { Cartão fidelidade com } \\
\text { acumulação de pontos }\end{array}$ & &, $115^{*}$ &, $170^{* * *}$ &, $139^{*}$ &, $291^{* *}$ &, $225^{* *}$ &, $158^{* *}$ \\
\hline $\begin{array}{l}\text { Oferta de } 1 \text { dormida na compra } \\
\text { de } 3\end{array}$ &, $121^{*}$ & &, $110^{*}$ &, $195^{* *}$ & $266^{* *}$ &, $223^{* *}$ &, $110^{*}$ \\
\hline
\end{tabular}

Legenda: $*(\mathrm{p}<0,05) ; * *(\mathrm{p}<0,01)$

Fonte: Autores.

Finalmente na Tabela 8 pode-se ver que para o hotel low-cost existem muito poucos coeficientes de correlação de Spearman positivos e significativos $(\mathrm{p}<0,01)$ entre os critérios de preferência na escolha de um hotel e a atitude em relação ao hotel (Ab), a intenção de reservar (PI), recomendação (WOM) o que significa a rejeição das hipótese H3a,b. Por outro, confirmando novamente a hipótese $\mathrm{H} 1$, no caso do hotel $5^{*}$, para quase todos os critérios de compra de um hotel, existem correlações positivas significativas $(\mathrm{p}<0,01)$ com a atitude em relação ao hotel ou com a intenção de compra, o que vem suportar nesta categoria de hoteis a hipótese H3a. É portanto uma conclusão interessante deste estudo, verificar que quando a categoria do hotel está associada ao preço premium, todas as componentes complementares do serviço hoteleiro ganham uma importância decisiva para a formação da atitude e da intenção de compra da dormida. 
Tabela 8 - Coeficientes de correlação de Spearman entre os critérios e medidas de resposta do consumidor (Ab, PI, WOM e WTP)

\begin{tabular}{|c|c|c|c|c|c|c|c|c|}
\hline & \multicolumn{4}{|c|}{ Hotel low cost $2 *$} & \multicolumn{4}{|c|}{ Hotel de luxo 5* } \\
\hline & $\mathrm{Ab}$ & $\mathrm{PI}$ & WOM & WTP & $\mathrm{Ab}$ & $\overline{P I}$ & WOM & WTP \\
\hline Recepção aberta 24 horas & & & & & $204^{* *}$ & $130^{*}$ & $155^{* *}$ & $146^{* *}$ \\
\hline Conforto & & & & & ,204** &, $207^{* * *}$ & ,209** & \\
\hline Higiene & & & & & & & &, $122^{*}$ \\
\hline Simpatia dos funcionários & & & & & $184^{* *}$ & $134^{*}$ & $208^{* *}$ & ,138* \\
\hline Qualidade das refeições & & & & & $201^{* *}$ &, $277^{* *}$ & $311^{* *}$ & $171^{* *}$ \\
\hline Serviço de quartos & & & & & $215^{* *}$ &, $211^{* * *}$ & $254^{* *}$ & ,129* \\
\hline Localização & &, $113^{*}$ & & & ,133* &, $115^{*}$ &, $116^{*}$ &, $116^{*}$ \\
\hline Piscina & & & & & $228^{* *}$ &, $380^{* *}$ & $276^{* *}$ & \\
\hline Spa &,$- 120^{*}$ & & & & $178^{* *}$ &, $370^{* *}$ &, $283^{* *}$ & \\
\hline Ginásio & & & & & $184^{* *}$ &, $333^{* *}$ & $264^{* *}$ & \\
\hline Decoração & & & & & 0,063 & $165^{* *}$ & $182^{* *}$ & \\
\hline Parque de estacionamento & & & & & $135^{*}$ &, $130^{*}$ & $164^{* *}$ & \\
\hline Acesso a transportes públicos & $196^{* *}$ & $249^{* *}$ & $186^{* *}$ & & $198^{* *}$ & & & \\
\hline $\begin{array}{l}\text { Acesso Wi-Fi gratuito, disponível } \\
\text { em todo o hotel }\end{array}$ & & & & & $195^{* *}$ & $120^{*}$ &, $132^{*}$ & \\
\hline $\begin{array}{l}\text { Comodidades para Pessoas com } \\
\text { Mobilidade Condicionada }\end{array}$ & & & & & $153^{* *}$ &, $148^{* *}$ &, $118^{*}$ & \\
\hline Admissão de animais de estimação & & & & & ,129* &, $174^{* *}$ & $123^{*}$ &, $113^{*}$ \\
\hline $\begin{array}{l}\text { Serviços de transportes de/para o } \\
\text { aeroporto }\end{array}$ & & & & & $200^{* *}$ & $176^{* *}$ & $169^{* *}$ & \\
\hline
\end{tabular}

Legenda: $*(\mathrm{p}<0,05) ; * *(\mathrm{p}<0,01)$.

Fonte: Autores.

\section{Conclusões}

A hotelaria é um serviço intangível, em que consumidor não pode experimentar o produto antes de o consumir e tem que se deslocar ao local de consumo. Por outro lado, a procura nesta indústria está sujeita à sazonalidade e às variações no rendimento dos consumidores. O preço é dos fatores mais importantes no marketing-mix pois: é o principal motivador da eleição/decisão de compra; é o único componente no marketing-mix que produz 
rendimento, enquanto os outros produzem custos; determina quotas de mercado; é independente dos outros fatores do marketing-mix.

A internet tornou-se um meio indispensável para o setor hoteleiro, quebrando várias barreiras de comunicação até então existentes. Hoje em dia é visível maior confiança por parte dos consumidores, tanto na execução de pagamentos como reservas online, na internet do que nas agências de viagem.

A nível hoteleiro é possível reconhecer que o gestor pode preferir vender todos os quartos ao preço mais elevado possível, sendo este caso pouco realizável, pois pode levar à perda de rendimentos caso não se consiga uma alta taxa de ocupação. Contrariamente a isto, se forem oferecidos quartos a um preço demasiado baixo, existe a possibilidade de serem todos ocupados, mas também pode haver perda de rendimentos, pois podiam ter sido vendidos a preços mais elevados.

Sendo o principal objetivo deste artigo analisar a influência do fator preço e avaliar a eficácia das táticas promocionais de preço do setor hoteleiro, é possível responder às questões de investigação colocadas no início do artigo.

Q1 -É necessário saber distinguir o conceito de valor e o conceito de preço e ter noção da utilidade que determinado produto/serviço irá ter para o cliente, de forma a conseguir alcançar os potenciais clientes e aqueles que são mais sensíveis ao preço. O cliente está preparado para a agressividade dos operadores, e está prevenido para alguma publicidade (enganosa), desde que perceba uma vantagem/desconto/oferta no serviço que está a comprar. Enquanto nos hotéis low-cost, o consumidor está preocupado pelos atributos funcionais e tangíveis como é o caso das acessibilidades, no caso dos hotéis de luxo, os consumidores querem estar informados que o prémio de preço que pagam será compensado por diversos benefícios relacionados com as caraterísticas do hotel, mas também com a simpatia dos funcionários.

Q2 - Principalmente no caso dos hotéis de luxo (4 e 5 estrelas), este estudo confirmou que as mensagens pop-up e as táticas promocionais podem influenciar decisivamente a atitude em relação ao hotel. Por outro lado, nalguns casos as mulheres atribuíram maior importância a estas táticas do que os homens.

Um gestor hoteleiro deve procurar compreender o processo de decisão e escolha do cliente (como por exemplo rotinas, preferências, atitudes) para perceber as motivações que contribuem decisivamente para a sua satisfação. Sem desinvestir nos fatores críticos de sucesso, como a decoração, higiene e conforto, importa prezar a qualidade do serviço, podendo investir 
Santos, E. S., \& Carvalho, M. J. (2020, set./dez.). Redes de colaboração científica e análise de políticas públicas desportivas locais no Brasil e em Portugal

em novos e melhores equipamentos. As táticas promocionais e as mensagens pop-up podem ser importantes para comunicar o fator de diferenciação se forem usadas com alguma moderação.

\section{Referências}

Abrate, G., Fraquelli, G., \& Viglia, G (2012). Dynamic pricing strategies: Evidence from European hotels. International Journal of Hospitality Management, 31, 160-168.

Abrate, G., \& Viglia, G. (2016). Strategic and tactical price decisions in hotel revenue management. Tourism Management, 55, 123-132.

Becerra, M., Santaló, J., \& Silva, R. (2013). Being better vs. being different: Differentiation, competition, and pricing strategies in the Spanish hotel industry. Tourism Management, 34, 71-79.

Buhalis, D., \& Mamalakis, E. (2015). Social media return on investment and performance evaluation in the hotel industry context. In Information and Communication Technologies in Tourism 2015 (pp. 241-253). Springer, Cham.

Cadotte, E. R., \& Turgeon, N. (1988). Key factors in guest satisfaction. Cornell Hotel and Restaurant Administration Quarterly, 28(4), 44-51.

Christou, E. (2011). Exploring online sales promotions in the hospitality industry. Journal of Hospitality Marketing \& Management, 20(7), 814-829.

Duman, T. (2002). A model of perceived value for leisure travel products. The Pennsylvania State University, College of Health and Human Development, A Thesis in Leisure Studies.

Enz, C. A., Canina, L., \& van der Rest, J.-P. (2015). Competitive hotel pricing in Europe: An exploration of strategic positioning [Electronic article]. Cornell Hospitality Report, 15 (2), 6-16.

Erdem, M., \& Jiang, L. (2016). An overview of hotel revenue management research and emerging key patterns in the third Millennium. Journal of Hospitality and Tourism Technology, 7(3), 300-312.

Fall, L. T. (2002). Examining the economic value of publicity and promotional activities among state tourism communication programs. Journal of Promotion Management, 8(2), $35-46$.

Guizzardi, A., Pons, F.M., \& Ranieri, E. (2017). Advance booking and hotel price variability online: Any opportunity for business customers? International Journal of Hospitality Management, 64, 85-93.

Kimes, Sheryl E. (2008). Hotel Revenue Management: Today and Tomorrow. vol.8, nº14, Cornell University School of Hotel Administration, Ithaca, New York, USA. 
Kotler, Philip (1998). Administração de Marketing: Análise, Planeamento, Implementação e Controle. São Paulo: Atlas.

Kuo, H. C., \& Nakhata, C. (2016). Price promotions and products with low consumer ratings. Journal of Consumer Marketing, 33(7), 517-527.

Lien, C. H., Wen, M. J., Huang, L. C., \& Wu, K. L. (2015). Online hotel booking: The effects of brand image, price, trust and value on purchase intentions. Asia Pacific Management Review, 20(4), 210-218.

Lindon D.; Lendrevie J.; Lévy J.; Dionísio P.; Rodrigues J. V. (2003). MERCATOR XXI, Lisboa, Publicações Dom Quixote, Lda..

Noone, B. M., McGuire, K. A., \& Rohlfs, K. V. (2011). Social media meets hotel revenue management: Opportunities, issues and unanswered questions. Journal of Revenue and Pricing Management, 10(4), 293-305.

Noone, B.M., \& Mattila, A. (2009). Hotel revenue management and the Internet: The effect of price presentation strategies on customers' willingness to book. International Journal of Hospitality Management, 28, 272-279.

Pereira, L. N. (2016). An introduction to helpful forecasting methods for hotel revenue management. International Journal of Hospitality Management, 58, 13-23.

Pereira, Luís N., \& Ferreira, Lara N. (2014). Determinantes da procura turística doméstica em Portugal numa conjuntura de crise económica e financeira. Tourism \& Management Studies, 10 (2), 75-83.

Rondan-Cataluña, F. J., \& Rosa-Diaz, I. M. (2014). Segmenting hotel clients by pricing variables and value for money. Current Issues in Tourism, 17(1), 60-71.

Trump, R. K. (2016). Harm in price promotions: when coupons elicit reactance. Journal of Consumer Marketing, 33(4), 302-310.

Ventura, R., \& Nogales, C. (2012). Revenue Management: Teoria e Prática de gerenciamento de receitas em hotelaria. $1^{a}$ edição, São Paulo: Edição dos autores.

Viglia, G., Mauri, A., \& Carricano, M. (2016). The exploration of hotel reference prices under dynamic pricing scenarios and different forms of competition. International Journal of Hospitality Management, 52, 46-55.

World Travel \& Tourism Council (WTTC) (2017). The authority on world travel \& tourism. [Internet], Disponível em https://www.wttc.org/-/media/files/reports/economic-impactresearch/regions-2017/world2017.pdf

Wyner, G. A. (2001). New pricing realities. Marketing Research, 13 (1), 34-35. 
Zhang, H., Fu, X., Cai, L., \& Lu, L. (2014). Destination image and tourist loyalty: A metaanalysis. Tourism Management, 40, 213-223. 